\title{
GRSA GEOCHEMICAL CHARACTERISTICS OF THE PSEUDOTACHYLITES OF MUSGRAVE PROVINCE
}

22-25 september CONNELLY, Daniel P., MAPCIS Research, 4815 Covered Bridge Rd, Millville, NJ 08332, SIKDER, Arif M., Center for Environmental Studies (CES), Virginia Commonwealth University
(VCU), 1000 West Cary Street, Richmond, VA 23284 TURNER AXS Inc., 5465 E. Cherym Parkway, Madison, WY 53711 and BRUM, Jose, Olympus Scientific Solutions Americas, 48 Woerd Ave, Suite 105, Waltham, MA 02452
AXS
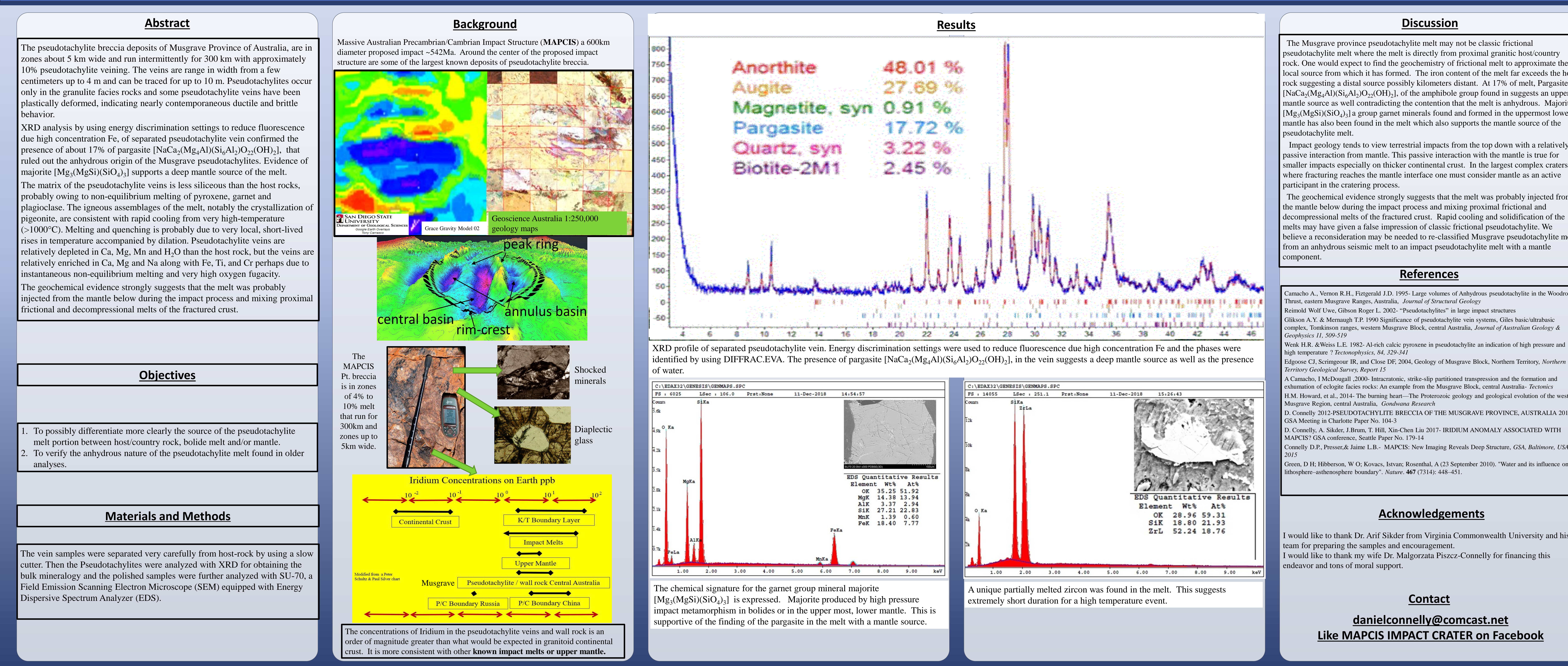